\title{
OPTIMASI RADIUS SERVER UNTUK PENGATURAN ALOKASI BANDWIDTH PADA JARINGAN HOTSPOT
}

\author{
I Putu Agus Eka Pratama, I Gede Bagus Premana Putra* \\ Fakultas Teknik, Universitas Udayana \\ email: baguspramana17@gmail.com
}

\begin{abstract}
Hotspot is one form of utilizing Wireless LAN technology that can be used to access internet services and is usually found in public areas such as libraries, campus internet parks, or offices. Aspects that need to be considered in hotspots to make users feel comfortable is security then at the provider side, the aspect that needs to be considered is the regulation of bandwidth allocation to optimize the data transfer speeds that the network and to prevent the possibility of dense network traffic. RADIUS server is one type of server that can be used at hotspots to secure hotspots because it supports various types of encryption. In this study, optimization of the settings for hotspot network bandwidth is optimized by integrating the RADIUS server with RouterOS. Bandwidth allocation management is done by determining the active time of a user account and set quotas hotspot uploads and downloads for the account. The results obtained from this study indicate that when a hotspot user account has passed the active time or has passed the upload quota and the download given, the account will be deleted from the list of hotspot user accounts or disabled.
\end{abstract}

Keywords: hotspot, RADIUS server, bandwidth allocation settings, routerOS

\section{PENDAHULUAN}

Komunikasi nirkabel atau tanpa kabel (wireless) merupakan salah satu kebutuhan yang tidak bisa dilepaskan dari kehidupan masyarakat pada era sekarang. Komunikasi tanpa kabel yang berkembang dimasyarakat memiliki banyak jenis salah satunya adalah LAN nirkabel atau yang lebih dikenal dengan sebutan Wi-Fi. Wi-Fi menjadi teknologi alternatif dan sangat mudah untuk diimplementasi diberbagai lokasi, seperti perkantoran, sekolah, laboratorium, atau di rumah sekalipun. Wi-Fi juga berkaitan erat dengan suatu area yang dapat dimanfaatkan untuk mengakses layanan Internet, sehingga tidak jarang Wi-Fi juga disebut dengan hotspot, terutama yang tersedia di wilayah public. Penggunaan jaringan Wi-Fi/hotspot juga lebih fleksibel karena perangkat yang ingin terhubung ke jaringan Wi-Fi/hotspot tidak perlu menggunakan kabel. Melihat banyaknya kemudahan yang ditawarkan oleh Wi-Fi/hotspot, menyebabkan banyak orang yang tertarik untuk menggunakannya (Priyamdo 2005).

Jaringan Wi-Fi/hotspot selain menyawarkan banyak kemudahan, teknologi ini juga memiliki kelemahan. Salah satu kelemahan atau dapat dikatakan sebagai suatu masalah yang akan dihadapi apabila menerapkan Wi-Fi adalah isu keamanan. Melihat hal tersebut, maka sampai sekarang masih banyak pihak yang mempertanyakan tentang sistem keamanan dari $\mathrm{Wi}-\mathrm{Fi}$, terutama dalam implementasinya. Apabila sistem keamanan ini diabaikan, maka terdapat kemungkinan adalah pengguna yang tidak berhak (illegal) dapat masuk atau menggunakan layanan yang dimiliki oleh hotspot (A. Ahmad 2015).

Manajemen pengguna juga merupakan permasalahan yang tidak bisa dilepaskan dari jaringan hotspot. Permasalahan ini lahir, karena jaringan hotspot sangat digemari oleh masyarakat dan mudah untuk digunakan, sehingga dapat dikatakan manajemen pengguna ini sebagai tantangan bagi administrator dalam implementasi hotspot. Manajemen pengguna yang dimaksud adalah yang pertama manajemen terhadap pengguna yang berhak mengakses layanan yang dimiliki jaringan (dapat diterapkan dengan sistem akun) dan manajemen kedua adalah pengaturan bandwidth, dengan tujuan untuk menghindari adanya kemungkinan monopoli bandwidth oleh user tertentu (M. Solikhul 2016).

Masalah keamanan yang dimiliki oleh jaringan hotspot dapat diatasi dengan mengintegrasikan atau menerapkan RADIUS 
(Remoter Access Dial In User Service) server. RADIUS pertama kali dikembangkan oleh Livingston Enterprise, yang selanjutnya disebut sebagai protokol keamanan jaringan dan dapat digunakan untuk manajemen akses Internet bagi client. RADIUS melakukan manajemen akses client dengan tiga metode yaitu otentikasi, otorisasi, dan pendaftaran akun pengguna secara terpusat. RADIUS menggunakan standar IEEE 802.1x atau sering disebut "Port Based Authentication" dan RADIUS beroperasi di layer aplikasi model referensi OSI (Hakan 2002).

RouterOS merupakan produk yang dikembangkan oleh Mikrotik yang diperuntukan sebagai network router. RouterOS dibuat dengan kernel Linux, sehingga membuat setiap perintah yang terdapat berbasis command line, RouterOS juga dapat diinstal pada PC yang menyebabkan PC tersebut dapat difungsikan sebagai router jaringan yang handal. RouterOS didesain untuk memberikan kemudahan bagi pengguna dan telah memiliki interfaces berbasis GUI melalui aplikasi WinBox. Fitur yang dimiliki oleh RouterOS sangat lengkap, terutama untuk membangun sebuah jaringan yang handal, adapun fitur tersebut diantaranya sebagai gateway Internet, routing, firewall, hotspot, sampai pengaturan alokasi bandwidth (Khoirul 2017).

Penelitian yang dilakukan oleh (A. Cristescu 2016) yaitu implementasi RADIUS server sebagai solusi untuk proses autentikasi yang legal. Pada penelitian ini dilakukan realisasi dari solusi mengenai authentication, authorization dan accounting user untuk mengakses internet pada sebuah jaringan wireless dengan memanfaatkan RADIUS server. RADIUS server yang diterapkan akan melakukan enkapsulasi paket dengan metode PAP, CHAP, MSCHAPv1 dan MSCHAPv2 untuk menciptakan suatu protokol atau algoritma yang mampu melindungi data user.

Penelitian selanjutnya oleh (A. Rahman 2016) yaitu implementasi manajemen bandwidth berbasis autentikasi user. Pada penelitian ini dilakukan implementasi RADIUS server yang diintegrasikan dengan Mikrotik untuk keperluan manajemen bandwidth yang mengambil studi kasus di Universitas Mulawarman. Cara implementasi yang dilakukan pada penelitian ini adalah dengan eksperimen untuk menciptakan suatu sistem yang mampu mengontrol dan mengalokasikan bandwidth kepada user berdasarkan jabatan (dosen, pegawai dan mahasiswa) saat mengakses jaringan Wi-Fi dan diintegrasikan dengan RADIUS server untuk keperluan autentikasi user yang legal.

Penelitian ini akan dilakukan optimasi pengaturan alokasi bandwidth dengan cara mengintegrasikan RADIUS server dengan Mikrotik RouterOS. Cara yang digunakan untuk pengaturan alokasi bandwidth adalah pertama menentukan masa aktif dari suatu akun pengguna jaringan hotspot dan kedua menentukan kuota upload serta download dari suatu akun pengguna jaringan hotspot, jika akun yang menggunakan atau terhubung dengan jaringan hotspot telah melewati batas waktu atau telah melewati batas kuota upload dan download yang telah ditentukan, maka akun tersebut akan di-disable dan hanya dapat digunakan kembali setelah dua jam dari waktu disable.

\section{METODE PENELITIAN}

Pembuatan sistem optimasi RADIUS server untuk manajemen bandwidth pada jaringan hotspot memerlukan beberapa metode penelitian, adapun metode yang digunakan pada penelitian ini adalah

1. Mendeskripsikan masalah utama dan menetapkan tujuan pokok dalam penelitian, yang sebelumnya sudah dijelaskan pada bagian pendahuluan.

2. Mengumpulkan data dan literatur yang diperlukan untuk memperkuat penelitian, yang dilakukan dengan beberapa metode berikut

a. Wawancara, wawancara dilakukan dengan pengguna layanan hotspot terkait tingkat kenyamanan layanan yang diterimanya, serta pihak pengelola layanan, untuk mengetahui cara yang diterapkan untuk melakukan manajemen user.

b. Studi pustaka, pencarian dan pengumpulan data yang diperlukan untuk memperkuat penelitian ini, baik berasal dari buku ataupun jurnal online. 
3. Pengembangan sistem optimasi RADIUS server yang terbagi menjadi 4 tahap, yaitu

a. Analisis kebutuhan sistem, dengan tujuan untuk mendefinisikan ruang lingkup dan perangkat keras serta lunak yang diperlukan dalam pengembangan sistem.

b. Desain, untuk menentukan desain topologi jaringan yang akan digunakan serta mendesain fungsi dari setiap interfaces yang dimiliki oleh perangkat keras.

c. Implementasi, merupakan tahap penerapan hasil analisis dan desain menjadi sistem optimasi RADIUS server, yang mana implementasi dilakukan dengan memanfaatkan virtualisasi.

d. Testing, untuk melakukan validasi dan verifikasi terhadap implementasi yang telah dilakukan.

\section{HASIL DAN PEMBAHASAN}

Hasil dan pembahasan yang akan dilakukan pada penelitian ini diawali dengan menganalisis kebutuhan sistem, membuat topologi sistem, menentukan fungsi dari setiap interfaces yang dimiliki oleh RouterOS, melakukan implementasi topologi sistem yang telah dibuat dan terakhir melakukan uji coba sistem.

\subsection{Analisis Kebutuhan Sistem}

Analisis kebutuhan sistem dilakukan dengan cara menentukan perangkat keras dan perangkat lunak yang diperlukan oleh sistem optimasi RADIUS server, yang dapat dijelaskan sebagai berikut.

Tabel 1 Kebutuhan Sistem

\begin{tabular}{|c|c|c|}
\hline No & Perangkat & Fungsi \\
\hline 1 & Sumber Internet & $\begin{array}{lr}\text { Sebagai } & \text { sumber } \\
\text { koneksi } & \text { internet } \\
\text { yang } & \text { akan } \\
\text { digunakan } & \text { oleh } \\
\text { client. } & \\
\end{array}$ \\
\hline 2 & RouterOS & $\begin{array}{l}\text { Pusat dari sistem, } \\
\text { yang memiliki fitur } \\
\text { untuk melakukan } \\
\text { manajemen user dan } \\
\text { bandwidth berbasis }\end{array}$ \\
\hline
\end{tabular}

\begin{tabular}{|c|c|c|}
\hline No & Perangkat & Fungsi \\
\hline & & RADIUS server. \\
\hline 3 & Access Point & $\begin{array}{l}\text { Sebagai pemancar } \\
\text { jaringan hotspot. }\end{array}$ \\
\hline 4 & Client & $\begin{array}{lr}\text { Diperlukan } & \text { saat } \\
\text { tahap testing, } & \text { untuk } \\
\text { verifikasi } & \text { dan } \\
\text { validasi } & \text { sistem } \\
\text { optimasi } & \text { RADIUS } \\
\text { server } & \text { pada } \\
\text { penelitian ini } & \end{array}$ \\
\hline
\end{tabular}

\subsection{Topologi Sistem}

Model topologi yang digunakan pada penelitian ini adalah topologi star. Mikrotik RouterOS menjadi pusat dari jaringan hotspot yang menghubungkan user dengan Internet. Mikrotik RouterOS yang digunakan juga telah dilengkapi dengan fungsi limitasi waktu penggunaan dan limitasi kuota upload serta download bagi user hotspot. Pengujian dilakukan terhadap fungsi limitasi waktu penggunaan (uptime), kuota upload (byte-in) dan kuota download (byte-out).

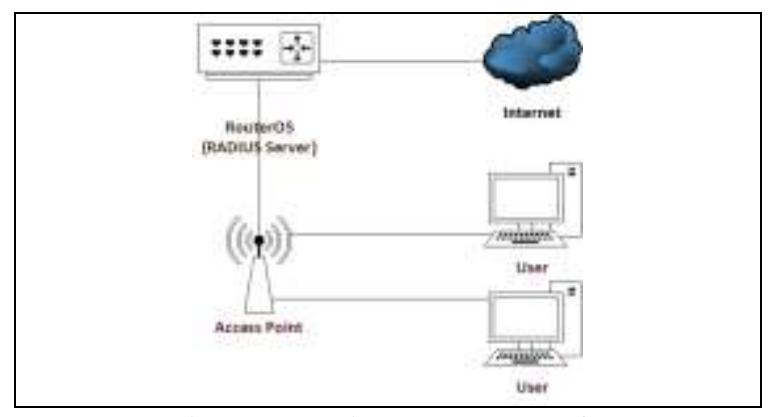

Gambar 1 Gambaran Umum Sistem

Gambar 1 menunjukkan topologi sistem dari penelitian yang akan digunakan. Topologi yang digunakan adalah star dengan RouterOS sebagai pusat jaringa hotspot yang menghubungkan client ke jaringan Internet dengan bantuan access point sebagai pemancar jaringan hotspot.

\subsection{Fungsi Setiap Interfaces RouterOS}

RouterOS yang digunakan pada penelitian ini telah diinstal pada PC dengan menerapkan metode virtualisasi menggunakan software VirtualBox. RouterOS yang telah diinstal memiliki tiga interfaces yang digunakan untuk keperluan jaringan hotspot, adapun 
detail dari interfaces yang dimiliki oleh RouterOS adalah seperti berikut.

Tabel 2 Fungsi Interfaces RouterOS

\begin{tabular}{|l|l|l|l|}
\hline No & $\begin{array}{c}\text { Nama } \\
\text { Interfaces }\end{array}$ & Mode & \multicolumn{1}{|c|}{ Fungsi } \\
\hline 1 & Ether-1 & NAT & $\begin{array}{l}\text { Menghubung } \\
\text { kan RouterOS } \\
\text { dengan } \\
\text { koneksi } \\
\text { internet yang } \\
\text { dimiliki oleh } \\
\text { PC }\end{array}$ \\
\hline 2 & Ether-2 & $\begin{array}{l}\text { Ter- } \\
\text { Bridge } \\
\text { Adapt } \\
\text { er }\end{array}$ & $\begin{array}{l}\text { Menghubung } \\
\text { kan RouterOS } \\
\text { dengan } \\
\text { Access Point } \\
\text { (AP berfugsi } \\
\text { sebagai } \\
\text { pemancar } \\
\text { hotspot) }\end{array}$ \\
\hline 3 & Ether-3 & $\begin{array}{l}\text { Menghubung } \\
\text { kan RouterOS } \\
\text { dengan PC } \\
\text { yang } \\
\text { digunakan } \\
\text { Ontuk } \\
\text { keperluan } \\
\text { konfigurasi }\end{array}$ \\
\hline
\end{tabular}

\subsection{Implementasi}

Implementasi dari jaringan hotspot dilakukan dengan menerapkan virtualisasi RouterOS pada PC sebagai router yang berfungsi sebagai controller jaringan hotspot. Jaringan hotspot yang telah dibuat juga telah diintegrasikan dengan RADIUS server yang dimiliki oleh RouterOS.

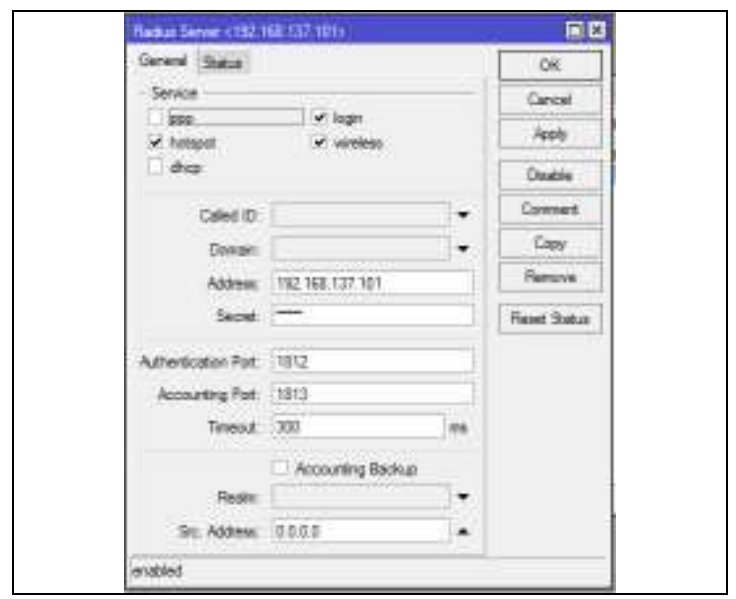

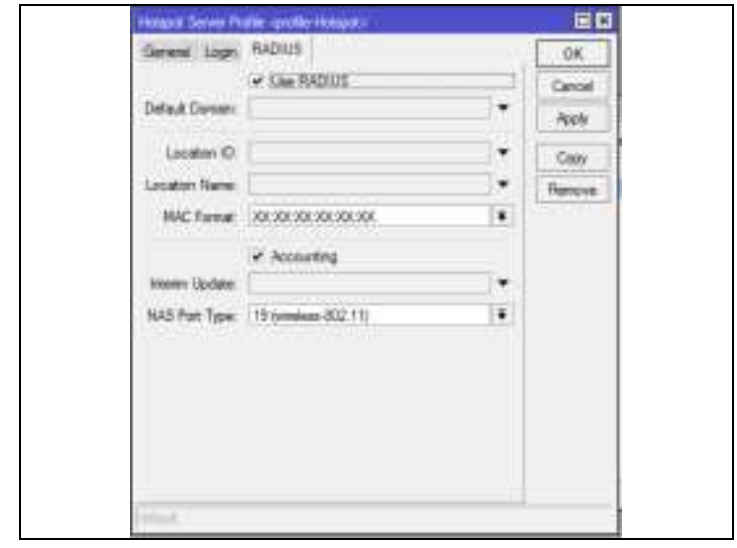

Gambar 2 Penggunaan RADIUS Server pada Jaringan Hotspot

Gambar 2 menunjukkan cara penggunaan atau integrasi jaringan hotspot dengan RADIUS server yang dimiliki oleh RouterOS.

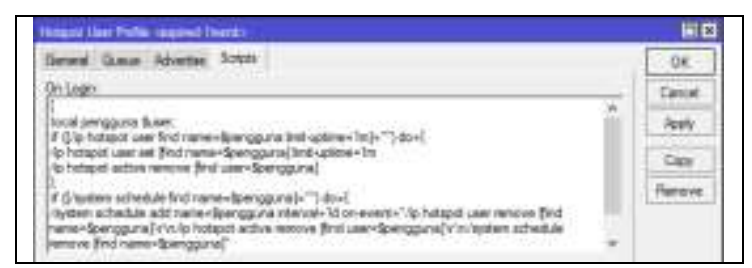

Gambar 3 Script Limitasi Batas Waktu Penggunaan Hotspot (Uptime)

Gambar 3 menunjukkan script yang digunakan untuk melakukan limitasi batas waktu penggunaan jaringan hotspot (uptime) bagi suatu user. Script untuk limitasi batas waktu penggunaan jaringan hotspot akan dijalankan secara otomatis ketika user telah berhasil melakukan login, maka dari itu script tersebut ditempatkan pada bagian on-login. Script limitasi uptime yang terdapat pada Gambar 3 akan menghapus user yang telah login ketika uptime-nya telah mencapai satu menit, kemudian user tersebut akan dihapus pada hari berikutnya untuk menghindari kemungkinan penyimpanan yang penuh dengan user yang sudah tidak aktif.

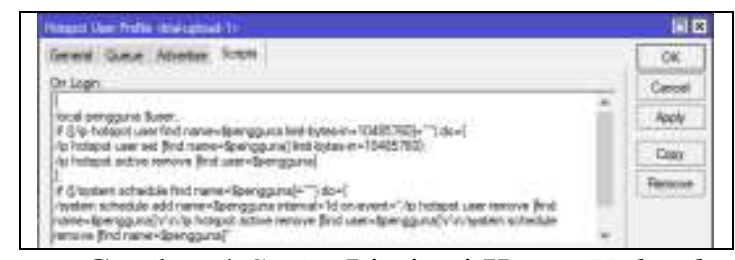

Gambar 4 Script Limitasi Kuota Upload (byte-in)

Gambar 4 menunjukkan script yang digunakan untuk melakukan limitasi kuota 
upload (byte-in) user hotspot ketika berhasil melakukan login. Script yang terdapat pada Gambar 4 akan menghapus user yang sedang aktif ketika kouta upload-nya telah mencapai $10 \mathrm{MB}$, kemudian user tersebut akan dihapus pada hari berikutnya.

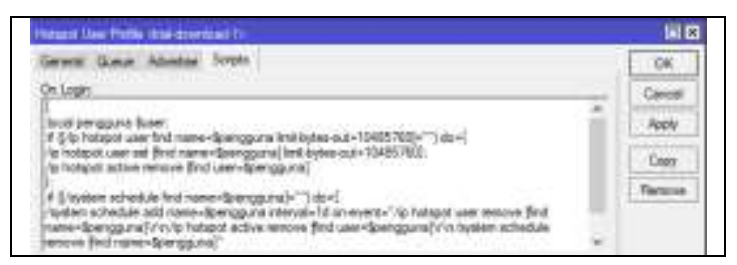

Gambar 5 Script Limitasi Kuota Download (byte-out)

Gambar 5 menunjukkan script yang digunakan untuk melakukan limitasi kuota download (byte-out) user hotspot ketika berhasil melakukan login. Script yang terdapat pada Gambar 5 akan menghapus user yang sedang aktif ketika kouta download-nya telah mencapai $10 \mathrm{MB}$, kemudian user tersebut akan dihapus pada hari berikutnya.

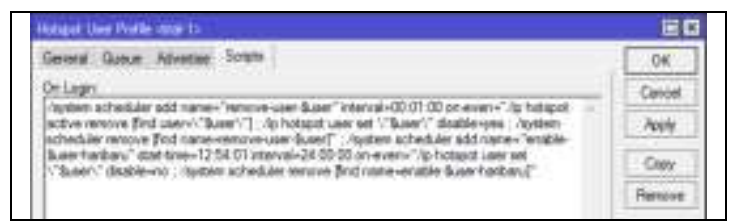

Gambar 6 Script User Trial

Gambar 6 menunjukkan script yang digunakan untuk menciptakan akun user yang bersifat trial. Script user trial akan membatasi waktu penggunaan layanan jaringan selama satu menit, setelah satu menit dari waktu login user tersebut akan dihapus dari daftar user aktif dan di-setting menjadi disable. Akun user akan aktif kembali pada hari berikut.

\subsection{Uji Coba}

Langkah selanjutnya setelah melakukan implementasi jaringan hotspot adalah uji coba jaringan hotspot yang telah dibuat pada sisi user. Akun user yang dapat digunakan untuk mengakses layanan jaringan hotspot adalah sebagai berikut.

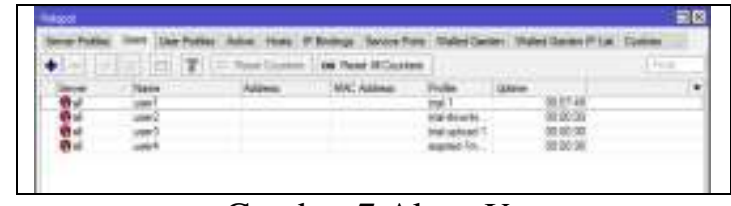

Gambar 7 Akun User

Gambar 7 menunjukkan akun yang dapat dipakai oleh user untuk mengakses jaringan hotspot. Akun user yang dimiliki oleh RouterOS berjumlah empat dengan profile yang berbeda sesuai dengan empat user profile yang dimiliki oleh RouterOS.

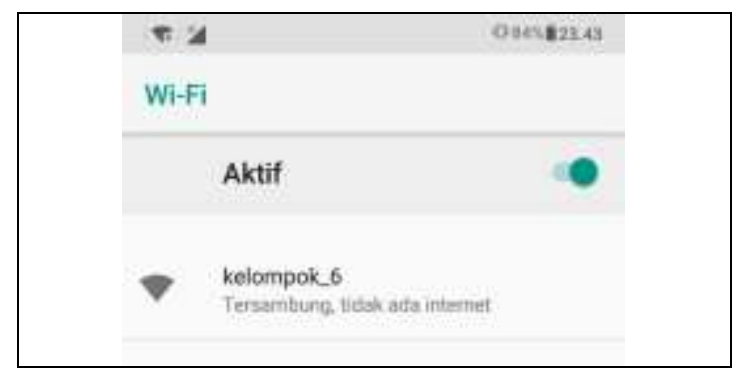

Gambar 8 Koneksi User ke Hotspot

Gambar 8 menunjukkan pengaksesan jaringan hotspot oleh user. Jaringan hotspot yang telah dibuat memiliki SSID kelompok_6.

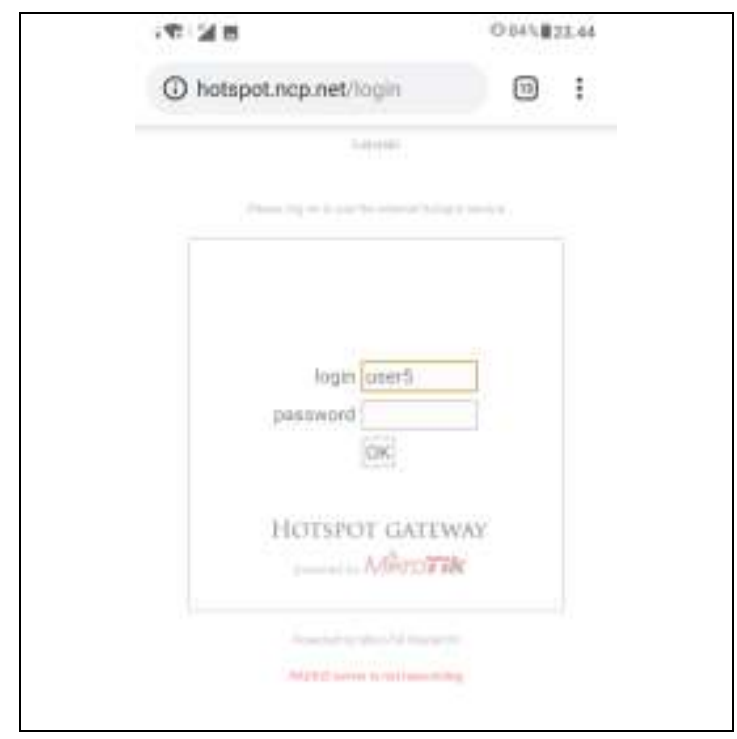

Gambar 9 Pesan Gagal Login

Gambar 9 menunjukkan pesan yang ditampilkan ketika user gagal melakukan login ke jaringan hotspot. Pesan yang ditampilkan pada Gambar 9 menunjukkan bahwa penerapan RADIUS server pada jaringan hotspot telah berhasil. 


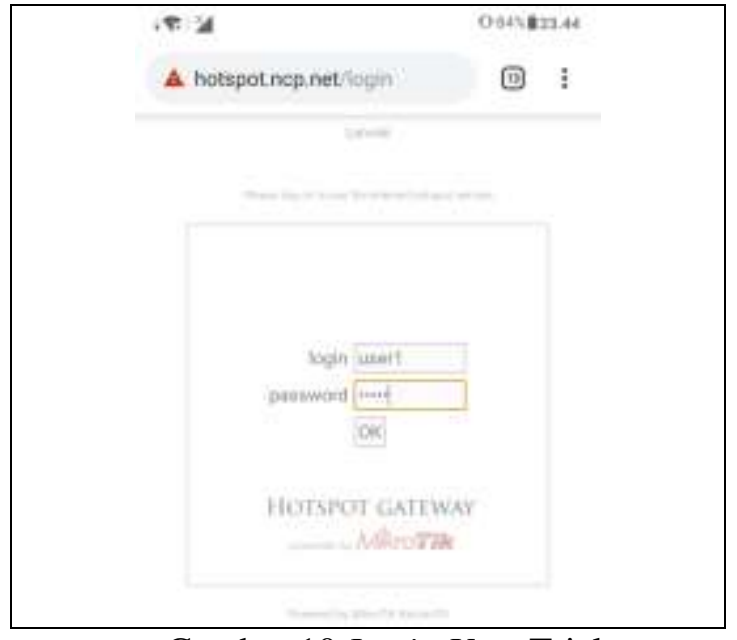

Gambar 10 Login User Trial

Gambar 10 menunjukkan user login dengan jaringan hotspot dengan akun yang bersifat trial. Akun yang bersifat trial akan memberikan user untuk menggunakan jaringan hotspot selama satu menit, setelah satu menit akun user akan di-disable dan dienable kembali pada hari berikutnya.

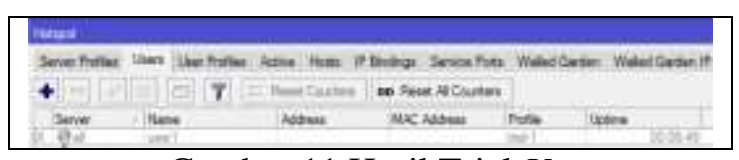

Gambar 11 Hasil Trial User

Gambar 11 menunjukkan akun trial user yang di-disable setelah satu menit. Akun tersebut akan di-enable kembali pada hari berikut.

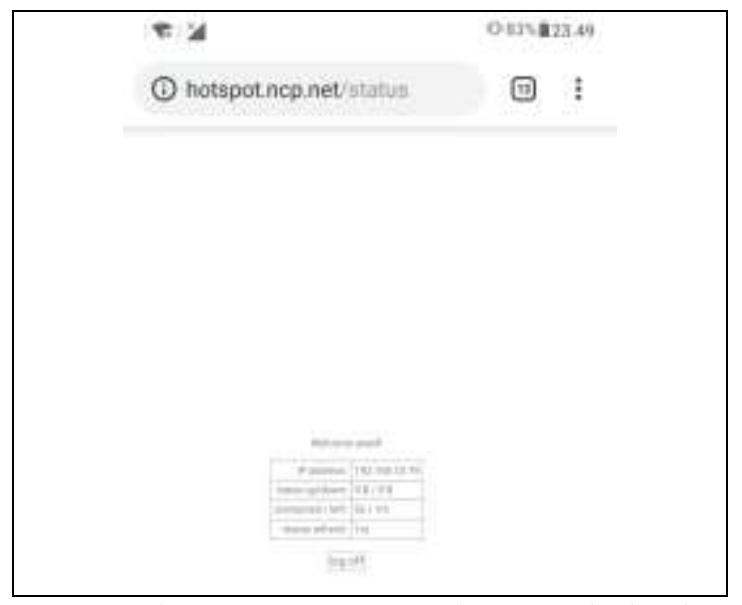

Gambar 12 Login User dengan Limitasi Uptime

Gambar 12 menunjukkan akun user yang berhasil login dengan limitasi uptime. Limitasi uptime akan menampilkan batas waktu penggunaan yang tersisa bagi user untuk menggunakan jaringan hotspot. Akun user yang telah mencapai batas limitasi uptime akan dihapus pada hari berikut.

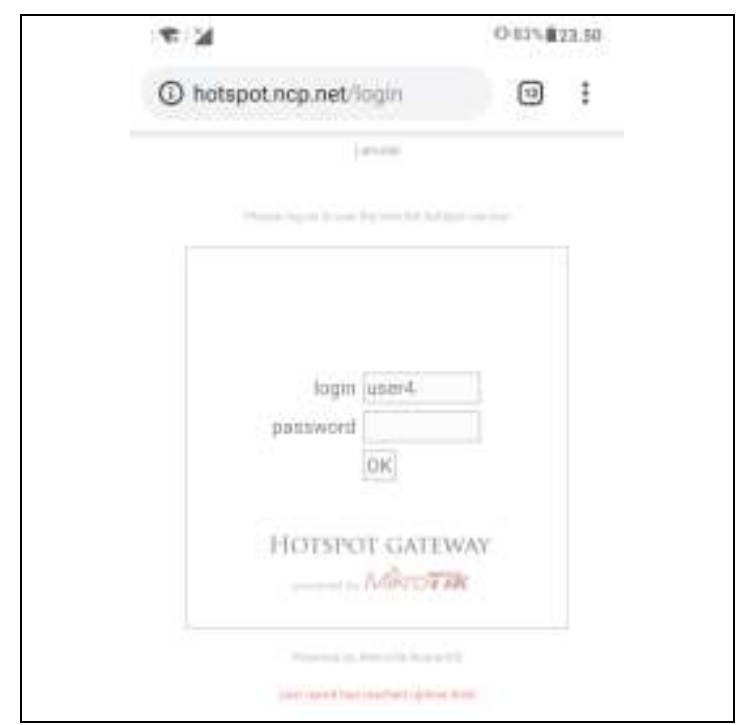

Gambar 13 Pesan Error Akun yang Telah Mencapai Uptime

Gambar 13 menunjukkan pesan yang ditampilkan ketika user telah mencapai batas waktu uptime yang telah ditentukan. Akun user yang telah mencapai batas uptime tidak bisa untuk login kembali dan akan ditampilkan pesan error berupa peringatan bahwa akun tersebut telah mencapai batas uptime dan dinyatakan sudah tidak aktif.

\section{KESIMPULAN}

Berdasarkan hasil dan pembahasan diatas, maka penulis dapat mengambil kesimpulan sebagai berikut.

1. Optimasi RADIUS server untuk pengaturan alokasi bandwidth merupakan sistem yang dibuat guna membantu administrator jaringan dalam melakukan pengamanan dan manajemen user terhadap pengguna layanan hotspot.

2. Security tambahan yang dapat diberikan pada jaringan hotspot untuk menangani autentikasi dan otorisasi user adalah RADIUS server.

3. Bandwidth manajemen user hotspot dapat dilakukan dengan memanfaatkan fitur script pada user profile Mikrotik hotspot.

4. Pengujian fungsi limitasi batas waktu penggunaan (uptime) layanan jaringan hotspot oleh user dapat dilakukan 
dengan memanfaatkan fitur script onlogin yang dimiliki oleh user profile RouterOS, yang mana pada bagian script ini dapat ditentukan limit-uptime yang ingin diberikan atau menggunakan sistem interval yang dihitung setelah user melakukan login.

5. Fungsi limitasi batas kuota upload dan batas kuota download juga dapat diterapkan dengan menggunakan fitur script on-login yang dimiliki oleh RouterOS, yang mana pada bagian script dapat ditentukan limit-byte-out untuk limitasi kuota download dan limit-byte-in untuk limitasi kuota upload.

\section{REFERENSI}

A. Ahmad, Kusnawi. 2015. Analisa Keamanan Jaringan Wireless Menggunakan Radius Server pada Mikrotik (Studi Kasus : Perpustakaan Universitas Gadjah Mada). Yogyakarta.

A. Cristescu, V. Sorici. 2016. "Implementing an AAA-RADIUS Solution Based on Legacy Authentication Protocols."
A. Rahman, Haviluddin. 2016. "Implementation of Bandwidth Management Authentication." Internation Journal of Compuring and Informatics (IJCANDI) 1-8.

Hakan, V. 2002. "DIAMETERNext Generation's AAA Protocol." www.diva-portal.org. Diakses November 2019, 16. http:www.divaportal.org/smash/get/diva2:18347/FU LLTEXT01.pdf.

Khoirul, A. 2017. Rancang Bangun Sistem Manajemen User Hotspot Menggunakan Mikrotik PHP API Berbasis Web di Pondok Pesantren Al-Luqmaniyyah. Yogyakarta: Universitas PGRI Yogyakarta.

M. Solikhul, T. I. Bayu. 2016. Perancangan dan Implementasi Manajemen User pada Jaringan Hotspot Mikrotik (Studi Kasus Kantor Perpustakaan dan Arsip Daerah Kota Salatiga). Salatiga: Universitas Kristen Satya Wacana.

Priyamdo, T.K dan Heriadi, D. 2005. Jaringan Wi-Fi Teori dan Implementasi. Yogyakarta: Andi. 